\title{
Perioperative fluid balance affects staging of acute kidney injury in postsurgical patients: a retrospective case-control study
}

Yu Horiguchi ${ }^{*}$, Akinori Uchiyama², Naoya Iguchi ${ }^{1}$ Kanaki Sakai ${ }^{1}$, Daisuke Hiramatsu' ${ }^{1}$, Kazuyoshi Ueta', Noriyuki Ohta ${ }^{1}$ and Yuji Fujino ${ }^{2}$

\begin{abstract}
Background: Although Acute Kidney Injury Network (AKIN) staging is widely used, it has been suggested that classification using serum creatinine levels, which fluctuate because of fluid balance, is not always appropriate for acute kidney injury (AKI) detection. We hypothesized that some patients are misdiagnosed as having no AKI due to dilution resulting from intraoperative infusion, and have worse outcomes than typical patients with no AKl.

Methods: We retrospectively selected patients who did not fulfill the AKI criteria from those who underwent cardiac surgery and remained in an intensive care unit (ICU) for $\geq 7$ days. The patients were divided into two groups: those with AKI (AKI group) and those without AKI (no-AKI group), classified using serum creatinine levels adjusted for fluid balance during the perioperative period. We compared the characteristics and outcomes of the two groups.
\end{abstract}

Results: After adjustment for serum creatinine, 7 of 26 patients were categorized as having AKI. The AKI group had significantly fewer ventilator-free days during a 28-day period and significantly longer ICU stays than the no-AKI group (5.86 \pm 10.0 days vs. $15.6 \pm 9.71$ days, respectively, $P=0.050 ; 36.4 \pm 20.6$ days vs. $14.9 \pm 10.7$ days, respectively, $P=0.033)$.

Conclusion: Adjustment of creatinine level for perioperative fluid balance could improve the accuracy of AKI diagnosis after cardiac surgery.

Keywords: Perioperative fluid management, Acute kidney injury, Serum creatinine levels

\section{Background}

Acute kidney injury (AKI) is a common complication in critically ill patients [1] that worsens outcomes [2]. The AKI Network (AKIN) proposed a clinical staging system that utilizes serum creatinine levels [3] and has been shown to predict outcomes [4]. However, a problem with using serum creatinine for AKI staging has recently been identified. Creatinine distributes into the intracellular and extracellular fluid compartments [5], so fluid accumulation may dilute creatinine and delay AKI diagnosis [6]. In patients with acute respiratory distress syndrome (ARDS), AKIN staging after adjustment by fluid balance

\footnotetext{
*Correspondence: yu_horiguchi1123@hotmail.com

${ }^{1}$ Intensive Care Unit, Osaka University Hospital, 2-15 Yamadaoka, Suita, Osaka 565-0871, Japan

Full list of author information is available at the end of the article
}

predicts outcomes more accurately than staging without adjustment, and patients meeting the AKI criteria only after adjustment have a higher mortality rate [7].

In perioperative patients, the incidence of AKI is $10 \%-$ $30 \%[1,8,9]$. Patients also develop positive fluid balance during surgery and on postoperative days (PODs) [10]. AKI staging may be underestimated in these patients, but there have been no reports regarding the AKIN criteria and fluid balance in perioperative patients. In this study, we investigated changes in AKIN staging using serum creatinine levels adjusted by perioperative fluid balance in patients who underwent cardiac surgery, who tend to accumulate more fluid. We used methods reported by Macedo et al. [6] to retrospectively adjust serum creatinine levels based on perioperative fluid balance, and made AKIN stage diagnoses based on adjusted 
levels in perioperative patients who did not meet the AKIN criteria based on unadjusted levels. We hypothesized that perioperative patients who met the AKIN criteria for stage 1 or higher after fluid adjustment would have poorer outcomes than those who were stage 0 both before and after fluid adjustment.

\section{Methods}

\section{Study population}

We examined patient records to retrospectively investigate patients who underwent cardiac procedures between January 2011 and July 2012, stayed in the intensive care unit (ICU) for at least 7 days, and did not develop AKI as determined by AKIN staging during their ICU stay. Patients with hemodialysis before surgery and patients under 18 years of age were excluded. This research was approved by the Ethics Committee of the Osaka University Graduate School of Medicine (approval number 12191).

\section{Definition of AKI}

We defined AKI using the AKIN consensus definition [3]. AKIN stage 1 disease is an increase in serum creatinine levels of $50 \%$ or an absolute increase of $\geq 0.3 \mathrm{mg} / \mathrm{dl}$ over a 48-h window during PODs $1-6$. The initial baseline creatinine level was obtained immediately before surgery; subsequently, a new baseline creatinine level, defined as the lowest value during the arbitrary 48-h window, was set before the increase in creatinine levels. We examined the incidence of AKI over the first 7 days of the study. To calculate adjusted creatinine levels, we first estimated the volume of distribution for creatinine levels before surgery, which was equal to total body water (TBW). We assumed that TBW was $60 \%$ of the patient's weight before surgery. For each study day, we used the 24-h fluid intake and output to calculate the cumulative fluid balance according to the following equation [6]:

$$
\text { Adjusted } \mathrm{Cr}=\mathrm{SCr} \times[1+(\text { Cumulative fluid balance } / \mathrm{TBW})] \text {, }
$$

where $\mathrm{SCr}$ is the measured serum creatinine level [7].

\section{Data collection}

The patients classified as having no AKI before adjustment were divided into two groups for analysis: no AKI and AKI after adjustment. Proportions were calculated for the frequency of categorical variables in each group. Age, sex, weight, new simplified acute physiology score (SAPSII) [11], type of surgery, time taken for the surgery, serum creatinine levels before surgery and at PODs 1-6, fluid balance and urine output at surgery and on PODs $0-5$, ventilator-free days within a 28-day period, ICU stay, hospital stay, serum creatinine levels on the 28th day, and renal replacement therapy on the 28th day were recorded.

\section{Statistics}

Descriptive statistics for categorical variables were expressed as the frequency and percentage, whereas continuous variables were expressed as means \pm standard deviations as appropriate. Fisher's exact test was used to compare categorical variables; the $t$ test was used to compare continuous variables. Measured unadjusted creatinine levels, adjusted creatinine levels, and fluid balance after surgery were analyzed by a twoway repeated measures analysis of variance. Tukey's post hoc test was performed to compare differences between groups on each POD. Tests were two-sided with the alpha level set at 0.05 for statistical significance.

\section{Results}

Twenty-six patients met the inclusion criteria of the study. After adjustment of creatinine levels, 19 patients did not meet the AKI criteria (no-AKI group) and seven patients (26.9\%) met the criteria (AKI group). Baseline characteristics of the two groups are shown in Table 1. Preoperative serum creatinine and SAPSII were similar in both groups. Durations of surgery and cardiopulmonary bypass (CPB) were significantly longer in the AKI group than in the no-AKI group $(544 \pm 164 \mathrm{~min}$ vs. $379 \pm 134 \mathrm{~min}$, respectively, $P=0.041 ; 316 \pm 145 \mathrm{~min}$ vs. $129 \pm 90.4 \mathrm{~min}$, respectively, $P=0.013)$. There were no significant differences

\section{Table 1 Patient characteristics}

\begin{tabular}{|c|c|c|c|}
\hline & $\begin{array}{l}\text { AKI group (AKI } \\
\text { after adjustment } \\
\qquad[n=7])\end{array}$ & $\begin{array}{l}\text { No-AKI group } \\
\text { (no AKI after } \\
\text { adjustment } \\
{[n=19] \text { ) }}\end{array}$ & $P$ value \\
\hline Age, years & $57.1 \pm 18.7$ & $54.2 \pm 20.2$ & 0.73 \\
\hline Male sex & 6 & 13 & 0.63 \\
\hline Body weight, kg & $61.2 \pm 5.29$ & $57.4 \pm 12.0$ & 0.28 \\
\hline SAPSII & $33.9 \pm 10.9$ & $30.3 \pm 7.17$ & 0.45 \\
\hline $\begin{array}{l}\text { Preoperative serum } \\
\text { creatinine levels, mg/dl }\end{array}$ & $1.14 \pm 1.11$ & $1.00 \pm 0.42$ & 0.76 \\
\hline \multicolumn{4}{|l|}{ Type of surgery } \\
\hline VAD implantation & 3 & 8 & \\
\hline CABG & 1 & 6 & \\
\hline Valve operation & 2 & 2 & \\
\hline Heart transplantation & 0 & 2 & \\
\hline TAA replacement & 1 & 0 & \\
\hline $\begin{array}{l}\text { Congenital heart } \\
\text { disease }\end{array}$ & 0 & 1 & \\
\hline Duration of surgery, min & $544 \pm 164$ & $379 \pm 134$ & 0.041 \\
\hline Duration of $\mathrm{CPB}$, min & $316 \pm 145$ & $129 \pm 90.4$ & 0.011 \\
\hline Use of CPB & 7 & 12 & 0.0041 \\
\hline $\begin{array}{l}\text { Fluid balance during } \\
\text { surgery, ml }\end{array}$ & $6,089 \pm 4,789$ & $2,629 \pm 2,116$ & 0.11 \\
\hline
\end{tabular}

Data are expressed as means \pm standard deviations. $V A D$ ventricular assist device, $C A B G$ coronary artery bypass grafting, TAA thoracic aortic aneurysm. 


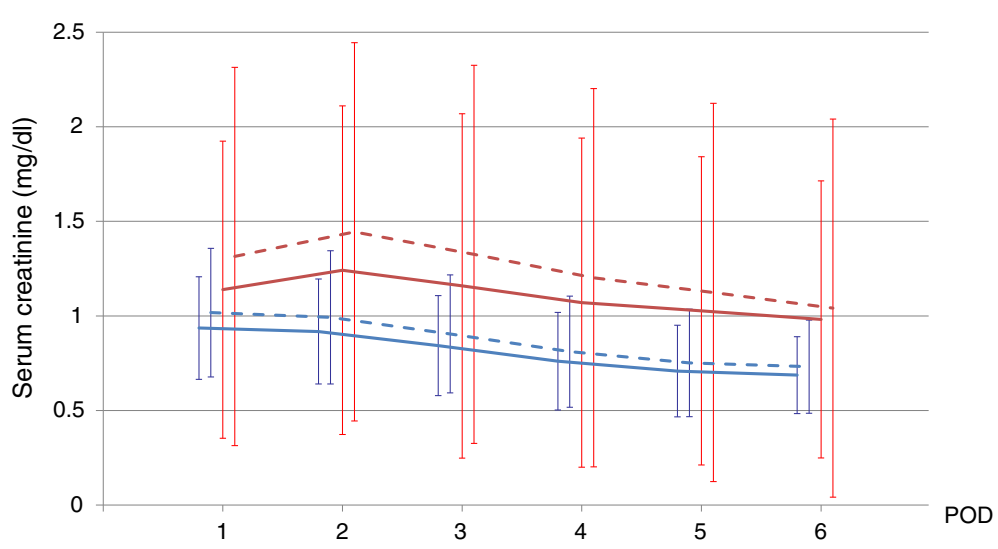

Figure 1 Unadjusted and adjusted serum creatinine levels. Blue solid and dashed lines show unadjusted and adjusted serum creatinine levels in the no-AKI group, respectively. Red solid and dashed lines show unadjusted and adjusted serum creatinine levels in the AKI group, respectively. There was a significant difference between unadjusted and adjusted serum creatinine levels at PODs $1-6(P<0.01)$. There was no significant difference between other groups.

in fluid balance during surgery $(6,090 \pm 4,790 \mathrm{ml}$ vs. $2,630 \pm 2,120 \mathrm{ml}$, respectively, $P=0.11$ ).

In the AKI group after adjustment, two patients reached AKIN stage 1 at POD 1, and five patients reached stage 1 at POD 2. No patients reached AKIN stage 2 or 3 after adjustment. There was a significant difference in serum creatinine levels and adjusted serum creatinine levels at PODs 1-6 $(P<0.01)$. There were no significant differences among groups (Figure 1).

Cumulative fluid balance from surgery in the AKI group was significantly higher than that in the no-AKI group $(P=0.0045)$, especially on POD $1(7,010 \pm 3,780 \mathrm{ml}$ vs. $2,610 \pm 2,540 \mathrm{ml}$, respectively, $P=0.021$; Figure 2 ). There was no significant difference in daily fluid balance $(P=$
0.082; Figure 3$)$ or in daily fluid administration $(P=0.32$; Figure 4).

Figure 5 shows urine output levels and drain fluid and blood loss levels for the patients during their ICU stay. There was no significant difference in urine output $(P=$ 0.089). Drain fluid and blood loss levels in the AKI group were significantly higher than those in the no-AKI group $(P=0.033)$. On PODs 4 and 5 , these levels were significantly higher in the AKI group $(513 \pm 362 \mathrm{ml}$ vs. $161 \pm 242 \mathrm{ml}$, respectively, $P=0.043 ; 395 \pm 214 \mathrm{ml}$ vs. $117 \pm 206 \mathrm{ml}$, respectively, $P=0.014)$.

Outcome variables are shown in Table 2. There were significantly fewer ventilator-free days in a 28-day period in the AKI group than in the no-AKI group (5.86 \pm

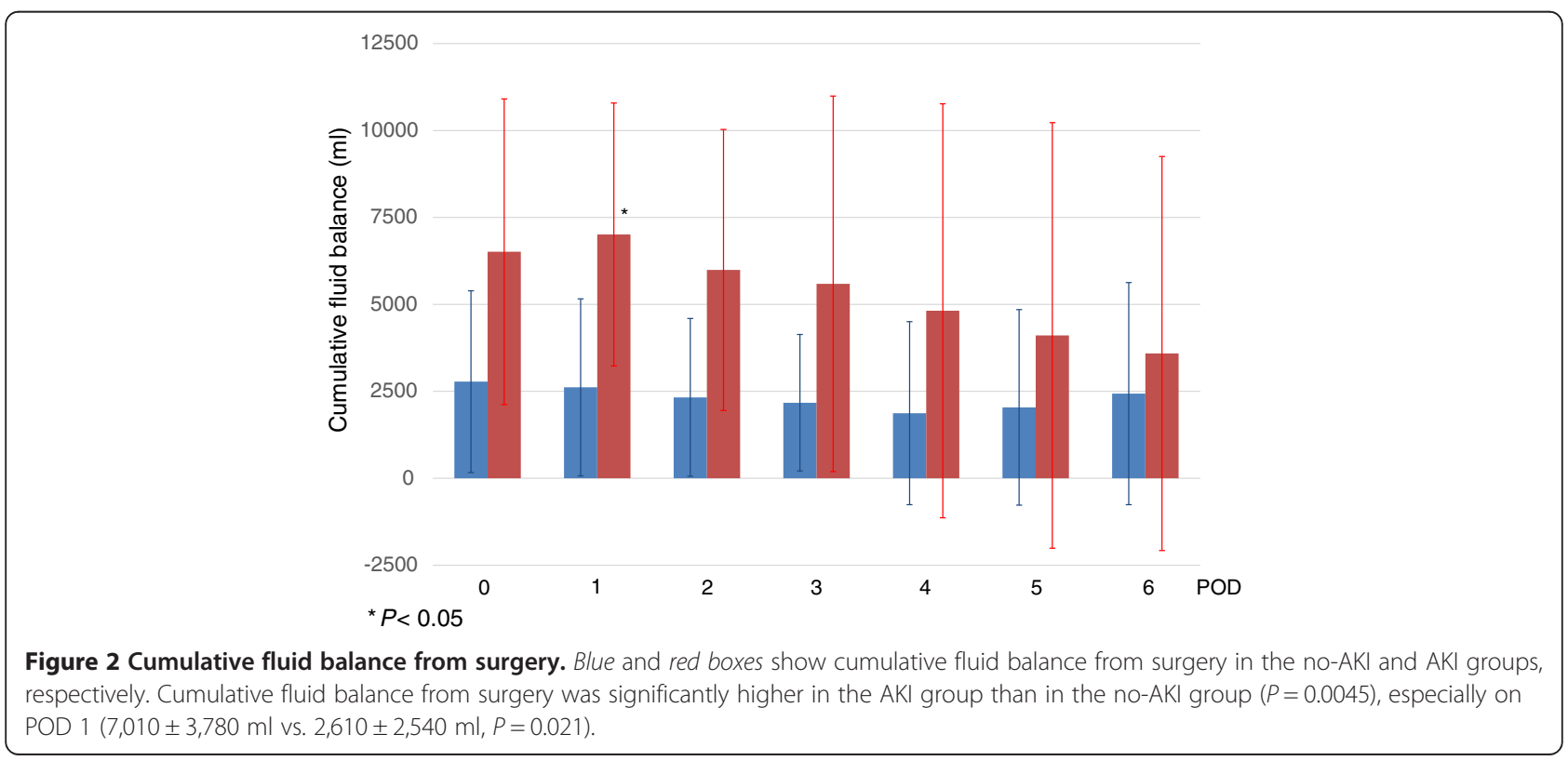




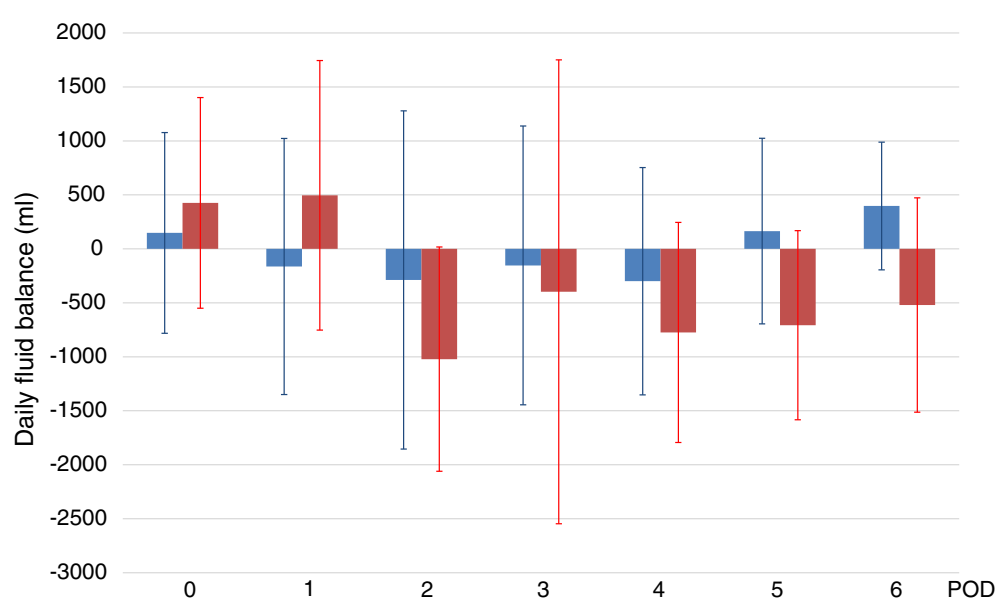

Figure 3 Daily fluid balance. Blue and red boxes show daily fluid balance in the no-AKI and AKI groups, respectively. There was no significant difference in daily fluid balance $(P=0.082)$.

10.0 days vs. $14.9 \pm 10.7$ days, respectively, $P=0.050$ ). ICU stays were significantly longer in the AKI group than in the no-AKI group $(36.4 \pm 20.6$ days vs. $14.8 \pm$ 10.7 days, respectively, $P=0.033$ ). There were no significant differences between the AKI and no-AKI groups in hospital stay length (207 \pm 176 days vs. $141 \pm 225$ days, respectively, $P=0.44$ ) or serum creatinine levels on the 28th day $(1.37 \pm 0.93 \mathrm{mg} / \mathrm{dl}$ vs. $0.78 \pm 0.28 \mathrm{mg} / \mathrm{dl}$, respectively, $P=0.15$ ). Two patients in the AKI group needed renal replacement therapy on the 28th day, while no patients in the no-AKI group needed renal replacement therapy; this difference was not statistically significant $(P=0.065)$.

\section{Discussion}

The study indicated that $26.9 \%$ of ICU patients diagnosed without AKI after cardiovascular surgery met the AKIN criteria after adjustment of serum creatinine levels based on perioperative fluid balance. These patients underwent more invasive surgery, as reflected by a longer duration of surgery and $\mathrm{CPB}$. Comparison of the AKI group with the no-AKI group after adjustment showed that the AKI group had poorer outcomes, fewer ventilator free-days within a 28-day period, and longer ICU stays than the no-AKI group.

Liu et al. evaluated AKI diagnosis based on serum creatinine levels adjusted for fluid balance in ARDS patients [7]. Of 459 ARDS patients, 131 met the AKIN criteria after adjustment, and the AKI group had a higher mortality rate. The results of the present study showed that the methodology of Liu's study was suitable for situations in which fluid balance changes dynamically, as it does during the perioperative period, in conditions other than ARDS. Although the original AKIN classification defined AKI using relative or absolute changes in serum creatinine levels without accounting for changes in fluid balance levels, both studies suggest that changes in renal function need to be interpreted in the context of fluid management.

Positive cumulative fluid balance is associated with poor outcomes in critically ill patients [12]. In our analysis, the AKI group after adjustment tended to have a

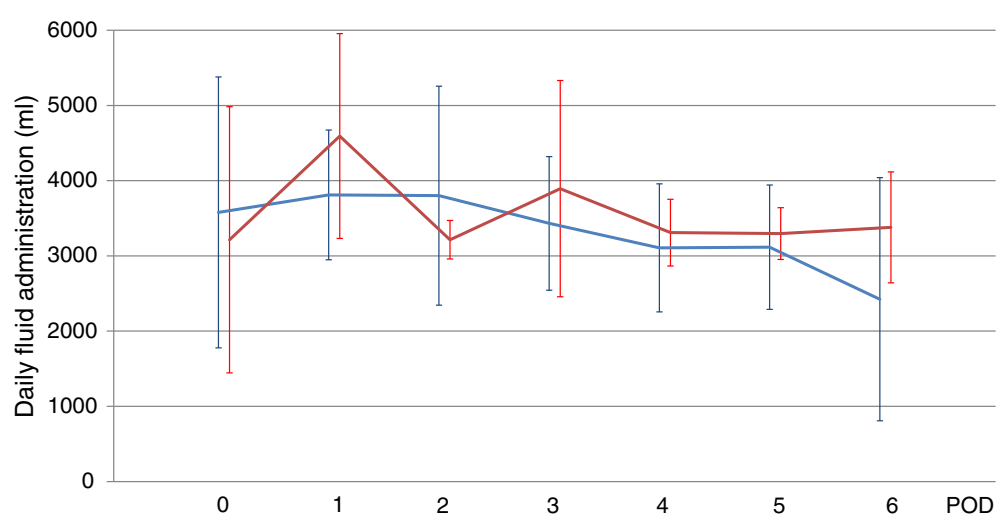

Figure 4 Daily fluid administration. Blue and red lines show total fluid administration in the no-AKI and AKI groups, respectively. There was no significant difference in daily fluid administration $(P=0.32)$. 


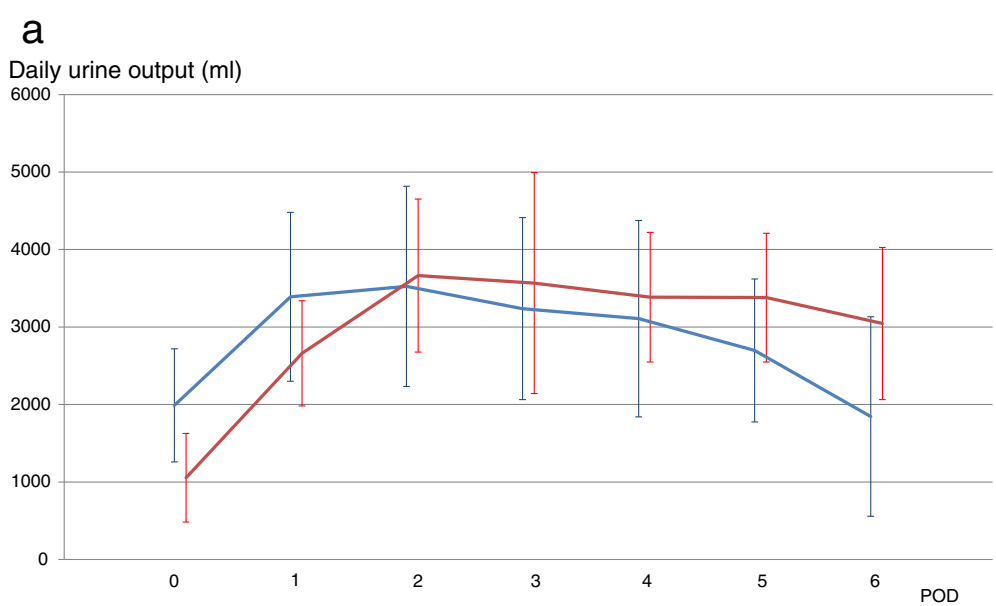

b

Drain fluid and blood loss $(\mathrm{ml})$

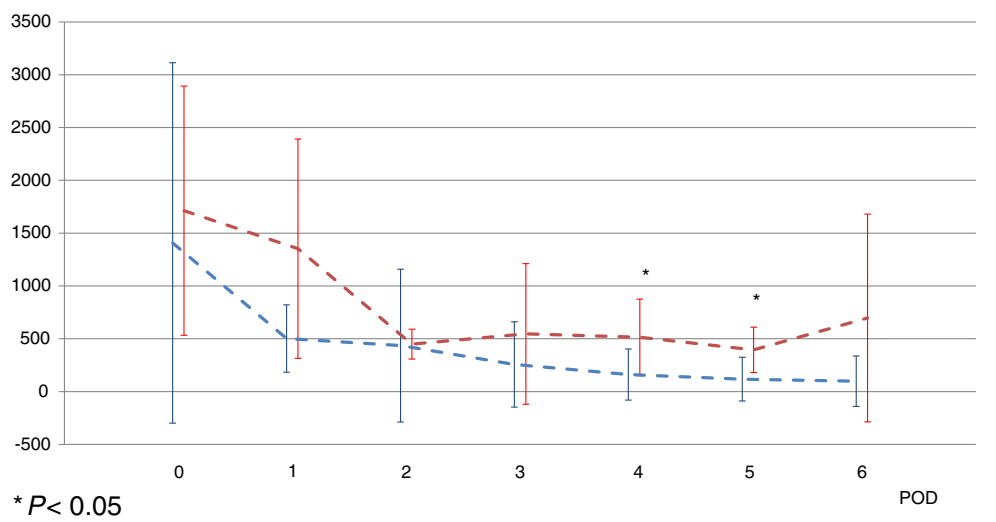

Figure 5 Daily urine output levels (a) and drain fluid and blood loss levels (b). Blue and red solid lines show urine output levels in the no-AKI and AKI groups, respectively. Blue and red dashed lines show drain fluid and blood loss levels in the no-AKI and AKI groups, respectively. There was no significant difference in urine output $(P=0.089$ ). Drain fluid and blood loss levels in the AKI group were significantly higher than those in the no-AKI group $(P=0.033)$. On PODs 4 and 5, these levels were significantly higher in the AKl group (513 $\pm 362 \mathrm{ml}$ vs. $161 \pm 242 \mathrm{ml}$, respectively, $P=0.043 ; 395 \pm 214 \mathrm{ml}$ vs. $117 \pm 206 \mathrm{ml}$, respectively, $P=0.014)$.

Table 2 Outcome variables

\begin{tabular}{lccc}
\hline & $\begin{array}{c}\text { AKI group } \\
\text { (AKI after } \\
\text { adjustment } \\
{[\boldsymbol{n}=\mathbf{7}] \text { ) }}\end{array}$ & $\begin{array}{c}\text { No-AKI group } \\
\text { (no AKI after } \\
\text { adjustment } \\
{[\boldsymbol{n}=\mathbf{1 9 ]})}\end{array}$ & $P$ value \\
\hline $\begin{array}{l}\text { Ventilator-free days within a 28- } \\
\text { day period }\end{array}$ & $5.86 \pm 10.0$ & $14.9 \pm 9.71$ & 0.050 \\
ICU stay, days & $36.4 \pm 20.6$ & $14.8 \pm 10.7$ & 0.032 \\
Hospital stay, days & $207 \pm 176$ & $141 \pm 224$ & 0.45 \\
$\begin{array}{l}\text { Serum creatinine levels on the } \\
\text { 28th day, mg/dl }\end{array}$ & $1.37 \pm 0.93$ & $0.78 \pm 0.28$ & 0.14 \\
$\begin{array}{l}\text { Renal replacement } \\
\text { therapy on the }\end{array}$ & 2 & 0 & 0.065 \\
28th day & & & \\
\hline
\end{tabular}

Data are expressed as means \pm standard deviations. more positive fluid balance than the no-AKI group, which may partly explain why the AKI group had poor outcomes. In our study, infusion and transfusion for bleeding, lower urine output due to AKI, or more infusion for treatment and prevention of AKI may have resulted in a more positive balance in the AKI group.

There are some limitations worth noting. First, this study was conducted using a retrospective design in a small number of patients from a single institution, and parameters were not analyzed by subgroups. Therefore, baseline characteristics were similar between the AKI and noAKI groups, although it is uncertain if other parameters, such as surgery type, bleeding, transfusion, or use of drugs such as catecholamines, may be related to outcomes. Further studies reviewing more patients are needed to confirm and extend our findings. Second, fluid balance during surgery, especially using $\mathrm{CPB}$, could be inaccurate due to incorrect counts of bleeding or 
infusion. Given that the duration of CPB was longer in the AKI group, fluid balance and adjusted serum creatinine could be less accurate than in the no-AKI group. Effects of adjustment are larger in patients with greater positive fluid balance and higher levels of previous creatinine. In patients with renal dysfunction, creatinine levels before adjustment are likely to be low because fluid balance tends to be more positive during perioperative days. Although there were no significant differences in preoperative creatinine levels between the AKI and no-AKI groups in our study, glomerular filtration rates before surgery might be different. Unfortunately, creatinine clearances were not measured in our patients, and thus, our results might not reflect the precise time courses of renal function deterioration in the perioperative periods. Measurement of creatinine clearance before and after surgery would help to obtain accurate influences of renal dysfunction. Finally, our data were also limited to patients diagnosed as AKIN stage 0 before adjustment for fluid balance. To investigate effects of adjustment in other AKIN stages, further studies are needed to compare all patients, including those diagnosed with AKI before adjustment.

\section{Conclusion}

During perioperative periods, AKIN staging can change after adjustment of creatinine levels for perioperative fluid balance, and adjusted AKIN staging could lead to more accurate AKI diagnosis. Positive fluid balance could underestimate AKI.

\section{Competing interests}

The authors declare that they have no competing interests.

\section{Authors' contributions}

YH drafted the manuscript. $\mathrm{NI}, \mathrm{KS}, \mathrm{DH}, \mathrm{KU}$, and $\mathrm{NO}$ participated in the design of the study and performed the statistical analysis. AU and YF conceived of the study, participated in its design and coordination, and helped draft the manuscript. All authors read and approved the final manuscript.

\section{Author details}

'Intensive Care Unit, Osaka University Hospital, 2-15 Yamadaoka, Suita, Osaka 565-0871, Japan. ${ }^{2}$ Department of Anesthesiology and Intensive Care

Medicine, Osaka University Graduate School of Medicine, Suita, Osaka 565-0871, Japan.

Received: 8 October 2013 Accepted: 6 March 2014

Published: 3 April 2014

\section{References}

1. Uchino S, Kellum JA, Bellomo R, Doig GS, Morimatsu H, Morgera S, Schetz M, Tan I, Bouman C, Macedo E, Gibney N, Tolwani A, Ronco C: Acute renal failure in critically ill patients: a multinational, multicenter study. JAMA 2005, 294:813-818.

2. de Mendonça A, Vincent JL, Suter PM, Moreno R, Dearden NM, Antonelli M, Takala J, Sprung C, Cantraine F: Acute renal failure in the ICU: risk factors and outcome evaluated by the SOFA score. Intensive Care Med 2000, 26:915-921.

3. Mehta RL, Kellum JA, Shah SV, Molitoris BA, Ronco C, Warnock DG, Levin A: Acute kidney injury network: report of an initiative to improve outcomes in acute kidney injury. Crit Care 2007, 11:R31.

4. Ostermann M, Chang R: Correlation between the AKI classification and outcome. Crit Care 2008, 12:R144.
5. Bjornsson TD: Use of serum creatinine concentrations to determine renal function. Clin Pharmacokinet 1979, 4:200-222.

6. Macedo E, Bouchard J, Soroko SH, Chertow GM, Himmelfarb J, Ikizler TA, Paganini EP, Mehta RL: Fluid accumulation, recognition and staging of acute kidney injury in critically-ill patients. Crit Care 2010, 14:R82.

7. Liu KD, Thompson BT, Ancukiewicz M, Steingrub JS, Douglas IS, Matthay MA, Wright P, Peterson MW, Rock P, Hyzy RC, Anzueto A, Truwit JD: Acute kidney injury in patients with acute lung injury: impact of fluid accumulation on classification of acute kidney injury and associated outcomes. Crit Care Med 2011, 39:2665-2671.

8. Thakar CV: Perioperative acute kidney injury. Adv Chronic Kidney Dis 2013, 20:67-75.

9. Thakar CV, Christianson A, Freyberg R, Almenoff P, Render ML: Incidence and outcomes of acute kidney injury in intensive care units: a Veterans Administration study. Crit Care Med 2009, 37:2552-2558.

10. Kambhampati G, Ross EA, Alsabbagh MM, Asmar A, Pakkivenkata U, Ejaz NI, Arif AA, Ejaz AA: Perioperative fluid balance and acute kidney injury. Clin Exp Nephrol 2012, 16:730-738.

11. Le Gall JR, Lemeshow S, Saulnier F: A new simplified acute physiology score (SAPS II) based on a European/North American multicenter study. JAMA 1993, 270:2957-2963.

12. Bouchard J, Soroko SB, Chertow GM, Himmelfarb J, Ikizler TA, Paganini EP, Mehta RL: Fluid accumulation, survival and recovery of kidney function in critically ill patients with acute kidney injury. Kidney Int 2009, 76:422-427.

doi:10.1186/2052-0492-2-26

Cite this article as: Horiguchi et al.: Perioperative fluid balance affects staging of acute kidney injury in postsurgical patients: a retrospective case-control study. Journal of Intensive Care 2014 2:26.

\section{Submit your next manuscript to BioMed Central and take full advantage of:}

- Convenient online submission

- Thorough peer review

- No space constraints or color figure charges

- Immediate publication on acceptance

- Inclusion in PubMed, CAS, Scopus and Google Scholar

- Research which is freely available for redistribution 